\title{
The effect of antimicrobial activity of Teucrium Polium on Oral Streptococcus Mutans: a randomized cross-over clinical trial study
}

Somayeh Khoramian Tusi ${ }^{1}$, Ahmad Jafari ${ }^{2,3^{*}}$ (D), Seyed Mahmoud Amin Marashi ${ }^{4}$, Salomeh Faramarzi Niknam ${ }^{1}$, Malihe Farid ${ }^{5}$ and Mehdi Ansari ${ }^{6}$

\begin{abstract}
Background: The purpose of this study is to determine the effect of a mouthwash containing Teucriumpolium herb on Streptococcus mutans in mouth.

Methods: This study was a randomized, crossover, double-blind clinical trial, where we selected 22 volunteers (dental students) randomly and we divided them into two groups. The study had two phases. In each phase, one group acted as the intervention group, while the other one was the control group. Both the intervention and control groups were given the mouthwash with and without Teucriumpolium, respectively. S. mutans of saliva were measured before and after each phase to compare the effects of the mouthwashes. A three-week washout period was considered between the two phases. An independent two-sample t-test was utilized to compare the mean of S. mutans colonies. Additionally, we used a standard AB/BA crossover model to find the results of the treatment and the impact of carryover on the residual's biological effects. The significance level was considered 0.05 in this experiment.
\end{abstract}

Results: There is no significant difference observed between the two groups in the number of S. mutans before using the mouthwashes. When the mouthwash containing Teucriumpolium was used, there was a significant decrease in the number of $S$. mutans colonies in both phases' extract $(P=0.002)$. Conclusion: The results of this study indicate the mouthwash containing aqueous extract of Teucrium polium can majorly reduce the colonization of $S$. mutans in human saliva.

Trial registration: Ethical issues approved by the Ethics Committee of the Rafsanjan University of Medical Sciences with the approval number of 937/9/31, IRCT code Number of IRCT2013121815842N1 and it was approved on 06/ 16/2014. The study was conducted in the period of September to November 2014.

Keywords: Mouthwash, Medicinal plants, Salvia, Herbal extract, Dental caries, Oral hygiene

\footnotetext{
* Correspondence: ajafari@tums.ac.ir

${ }^{2}$ Research Center for Caries Prevention, Dental Research Institute,

Department of Community Oral Health, School of Dentistry, Tehran

University of Medical Sciences, Tehran, Iran

${ }^{3}$ Department of Pediatric Dentistry, School of Dentistry, Al Hussain University,

Karbala, Iraq

Full list of author information is available at the end of the article
}

(c) The Author(s). 2020 Open Access This article is licensed under a Creative Commons Attribution 4.0 International License, which permits use, sharing, adaptation, distribution and reproduction in any medium or format, as long as you give appropriate credit to the original author(s) and the source, provide a link to the Creative Commons licence, and indicate if changes were made. The images or other third party material in this article are included in the article's Creative Commons licence, unless indicated otherwise in a credit line to the material. If material is not included in the article's Creative Commons licence and your intended use is not permitted by statutory regulation or exceeds the permitted use, you will need to obtain permission directly from the copyright holder. To view a copy of this licence, visit http://creativecommons.org/licenses/by/4.0/. The Creative Commons Public Domain Dedication waiver (http://creativecommons.org/publicdomain/zero/1.0/) applies to the data made available in this article, unless otherwise stated in a credit line to the data. 
effect for polei-gamander plant has been widely reported in different studies. Mosadegh et al. [31] reported a weak antibacterial effect of ethanolic extract of poleigamander plant on Staphylococcus, Micrococcus luteus, and Escherichia coli, while the antibacterial effect in our research was strong. The differences in such reports might be due to various types of bacteria, and different extraction methods.

Phenolic compounds which are present in T. polium herb could be the factor which is reducing the number of salivary $S$. mutans. Bravo showed that gram-positive and gram-negative bacteria are sensitive to the phenolic compounds, which are widely distributed substances in many plants [32]. Antimicrobial effects of these compounds depend on the number and the position of the phenol hydroxyl groups. It has been claimed that the toxicity effect of these compounds on the microorganisms is directly correlated with the numbers of hydroxyl groups [33]. Another antimicrobial component existing in T. polium herb is tannin compound. Antimicrobial effects of these compounds are due to both suppression of tenacity of the microbes and blockage of microbial enzymatic activity [34].

Our study exhibited a positive result, nonetheless, the effects of T. polium mouthwash has not been compared to chlorhexidine as a gold standard. It is highly suggested to investigate and to compare the effect of poleigamander plant's active ingredients on different bacterial strains with that of chlorhexidinein the upcoming researches.

\section{Conclusion}

The results of the current research indicate the aqueous extract of $T$. polium significantly reduces the colonization of $S$. mutans in human saliva. This decline was visible even after three weeks of washout period. Overall, it can be concluded the use of $T$. polium mouthwash, on a periodic basis, can reduce the risk of tooth decays. These findings can also contribute to the ingredients of other oral hygiene materials like toothpastes or chewing gums.

\section{Supplementary information}

Supplementary information accompanies this paper at https://doi.org/10. 1186/s12903-020-01116-4.

Additional file 1

Additional file 2. Standard AB/BA crossover model analysis.

\section{Abbreviations}

S. mutans: Streptococcus mutans; T. polium: Teucrium polium; IRCT: Iranian Registry of Clinical Trials; TYCSB: Tryptone-Yeast-Cysteine-Sucrose-Bacitracin; VP: vogues-proskauer; CFU: colony forming unit; CONSORT: Consolidated Standards of Reporting Trials

\section{Acknowledgments}

The authors wish to thank Rafsanjan University of Medical Sciences for their all supports and to be grateful for students' participating in the study.

\section{Authors' contributions}

SKT made contributions to the conceptual design of the work, and also drafted the work and revisedearly drafts. AJ made contributions to the conceptual design of the work, and also drafted the work and revised early drafts and submitted the manuscript. SMAM made contributions to supervise the microbial tests. SFN wrote the manuscript and revised early drafts. MF helped in the acquisition, analysis, and interpretation of data. MA made contributions to prepare the extract of Teucriumpolium and mouthwashes. All authors read and approved the final manuscript.

\section{Funding}

No funding was obtained for this study.

Availability of data and materials

Data of this study is attached as a Microsoft excel file.

\section{Ethics approval and consent to participate}

The present study was approved by the Ethics Committee of Rafsanjan University of Medical Sciences with the approval number of 937/9/31 and Iranian Registry of Clinical Trials (IRCT) code No. IRCT2013121815842N1. All the participants signed a written informed consent form. Attendance in this study was not compulsory and the participants did not receive any course credits for attending.

\section{Consent for publication}

Not applicable.

\section{Competing interests}

The authors declare that there are not any competing interests.

\section{Author details}

${ }^{1}$ Department of Pediatric Dentistry, School of Dentistry, Alborz University of Medical Sciences, Alborz, Iran. ${ }^{2}$ Research Center for Caries Prevention, Dental Research Institute, Department of Community Oral Health, School of Dentistry, Tehran University of Medical Sciences, Tehran, Iran. ${ }^{3}$ Department of Pediatric Dentistry, School of Dentistry, Al Hussain University, Karbala, Iraq. ${ }^{4}$ Department of Microbiology, Qazvin University of Medical Sciences, Qazvin, Iran. ${ }^{5}$ Department of Community Medicine, School of Medicine, Alborz University of Medical Sciences, Alborz, Iran. ${ }^{6}$ Department of Pharmaceutics, Faculty of Pharmacy, Kerman University of Medical Sciences, Kerman, Iran.

Received: 28 January 2020 Accepted: 19 April 2020

Published online: 01 May 2020

\section{References}

1. Farrell JJ, Zhang L, Zhou H, Chia D, Elashoff D, Akin D, et al. Variations of oral microbiota are associated with pancreatic diseases including pancreatic cancer. Gut. 2012:61(4):582-8.

2. Weidlich P, Cimões R, Pannuti CM, Oppermann RV. Association between periodontal diseases and systemic diseases. Brazilian Oral Res. 2008:22:3243.

3. Meyer K, Geurtsen W, Günay H. An early oral health care program starting during pregnancy. Clin Investig. 2010;14(3):257-64.

4. Palombo EA. Traditional medicinal plant extracts and natural products with activity against oral bacteria: potential application in the prevention and treatment of oral diseases. Evid Based Complement Alternat Med. 2011; 2011:1-15.

5. Vlachojannis $\mathrm{C}$, Winsauer $\mathrm{H}$, Chrubasik S. Effectiveness and safety of a mouthwash containing essential oil ingredients. Phytother Res. 2013;27(5): 685-91.

6. Emmadi P, Ambalavanan N, Ramakrishnan T, Vijayalakshmi R. Effect of three commercial mouth rinses on cultured human gingival fibroblast: and in vitro study. Indian J Dent Res. 2008:19(1):29.

7. James P, Worthington HV, Parnell C, Harding M, Lamont T, Cheung A, Whelton $\mathrm{H}$, Riley $\mathrm{P}$. Chlorhexidine mouthrinse as an adjunctive treatment for gingival health. Cochrane Database Syst Rev. 2017;3:25-6. 